\title{
Interaction between Organic and Inorganic PCMs and Selected Metals
}

\author{
Sylva Bantová ${ }^{1}$, Milan Ostrý ${ }^{2, *}$, Karel Struhala ${ }^{3}$ \\ 1 Brno University of Technology, Faculty of Civil Engineering, 60200 Brno, Czech Republic; \\ bantova.s@fce.vutbr.cz \\ 2 Brno University of Technology, Faculty of Civil Engineering, 60200 Brno, Czech Republic; \\ ostry.m@fce.vutbr.cz \\ 3 Brno University of Technology, Faculty of Civil Engineering, 60200 Brno, Czech Republic; \\ struhala.k@fce.vutbr.cz \\ * Correspondence: ostry.m@fce.vutbr.cz; Tel.: +420-541-147-499 (O.M.)
}

\begin{abstract}
Phase Change Materials (PCMs) are latent heat storage media with high potential of integration in building structures and technical systems. Their solid-liquid transition is commonly utilized for thermal energy storage in building applications. It also means that some kind of encapsulation is necessary. This is often solved with metal containers that also have high thermal conductivity and resistance to mechanical damage enhancing the performance these so called latent heat thermal energy storage (LHTES) systems. However selection of suitable metal is rather challenging. It depends, among other things, on the elimination of undesirable interaction between storage medium and surrounding metal. Heat storage medium must be reliably sealed in metal container especially when the storage system is integrated in systems like domestic hot water storage tanks, where PCM leaks can negatively affect human health. The aim of this study was evaluation of interaction between selected commercially available organic and inorganic PCMs and metals. The evaluation is based on the calculation of corrosion rate and use gravimetric method for determination of the weigh variations of the metal samples. Results show that aluminium is the most suitable container material with lowest mass loss and suffered only minimal visual changes on the surface after prolonged exposure to PCMs.
\end{abstract}

Keywords: Phase Change Materials (PCMs); metals; container; latent heat storage; corrosion

\section{Introduction}

Latent heat thermal energy storage (LHTES) systems use reversible phase change in the storage medium. Although the heat of fusion predominates a lot of heat is stored in solid and liquid state by sensible heat storage. LHTES has the potential to replace common sensible heat storage (SHS; often represented by water tanks) in energy storage units due to higher heat storage density. Therefore the major advantage of LHTES over SHS is much higher energy storage capacity per unit of volume or mass leading to lower spatial requirements. Heat storage in almost isothermal conditions is another advantage of LHTES, [1]. These reasons suggest that application of LHTES could be advantageous in solar thermal systems, heating and cooling systems, building structures, thermal regulating textiles (smart textiles), concentrated solar power systems, food services, thermal management of automotive engines, spacecraft thermal control, and other technologies, [3].

Substances which are ready for use in LHTES systems are called Phase Change Materials (PCMs). Suitable PCMs have temperature range of melting and solidification in accordance with the proposed application, high heat of fusion, and is safety for use, inexpensive and reliable. The fact that PCMs transform from solid to liquid state during operation necessitates appropriate encapsulation. One option is so called macroencapsulation. It represents a common method of mechanical packaging [2] where the PCM is filled into a macro-capsule (container) of required shape 
and size. The geometry of the container, material and thickness of its walls all depend on the intended purpose of the particular LHTES system. Design of these parameters is crucial for flawless heat exchange between the PCM and surrounding environment as well as reliability and durability of the system. There are three major issues affecting reliability of LHTES [4, 5, 6 ]:

- tightness of the container as migration of PCM or components can lead to loss of heat storage capacity or undesirable interaction with indoor environment;

- stability of the container in contact with PCM - e.g. corrosion of metals due to exposition to PCM can occur;

- elimination of reaction between PCM and container - material of container must be chemically compatible with PCMs.

These issues suggest that compatibility of heat storage media with encapsulating material is a key parameter if long service life of LHTES should be ensured. Moreover container must have necessary strength and be flexible due to the stresses resulting from the volume changes during phase change. Material of container must be stable to UV exposure and allow rapid heat transfer for charging and discharging of PCMs. Metals are therefore often suggested as container material, especially in cases of PCMs with high melting range when other solutions (commonly plastics) cannot be utilized. Metals have high thermal conductivity and regular crystalline structure serving as barrier for diffusion of small gas molecules. On the other hand they are susceptible to corrosion. Three types of PCM-induced corrosion of metals can occur, [6]:

- $\quad$ oxidation of the metal - PCM corrupts porous surface layer of the container, which leads to its uniform perforation (typical for mild steel);

- $\quad$ pitting corrosion - corrosion starts at a point, accelerates and produces deep "pits" (typical for stainless steel, aluminium and coated metals with pinholes);

- $\quad$ stress crack corrosion - corrosion occurs at stress region and results in sudden failure (typical for stainless steel).

Uniform corrosion is commonly determined by weight loss tests. Pitting corrosion requires microscopic evaluation of depth and extension of the corroded pits.

There are already numerous studies evaluating compatibility of PCMs with container materials, [7]. Most of these studies focus on the compatibility between organic and inorganic PCMs with carbon steel, aluminium, copper, brass and stainless steel. The corrosion resistance of metals exposed to PCMs in low temperature LHTES is commonly assess by calculatied corrosion rates (CR) in these studies, [8]. The procedure applied for preparing of metal samples for removing corrosion products and for evaluating the corrosion damage of specimens is describes in ASTM G1 [9].

The assessment of the compatibility between PCM (magnesium nitrate - PlusIce S83) and three metals (aluminium alloy, copper alloy and carbon steel) was presented by Calabrese $e t$ al. [10]. They performed short-time immersion corrosion tests at $120^{\circ} \mathrm{C}$ and used two electrochemical methods for evolution of metal degradation during immersion in PCM: open circuit potential measuring and electrochemical impedance spectroscopy. Electrochemical activity of metals immersed in PCM was analysed by evolution of the impedance curves at increasing immersion time. Results of the study indicate that carbon steel and copper alloy are unsuitable container materials due to their low electrochemical stability. Aluminium alloy was evaluated as a suitable material for encapsulation of selected PCM. Farrell et al. [11] examined corrosion resistance of aluminium alloy and copper in contact with commercially available salt hydrate PCMs PlusICE E17 and ClimSel C18. Firstly, they tested separate samples of each metal immersed in the PCMs. The results of this test show higher mass loss of copper samples. Secondly, they tested galvanic corrosion of combined samples of aluminium alloy and copper immersed in the PCMs. Authors concluded that aluminium fins combined with copper heat pipes in a heat exchanger are prone to galvanic corrosion caused by both examined PCMs. Cabeza et al. [12] tested five metals (aluminium, brass, copper, steel and stainless steel) in contact with selected salt hydrates (zinc nitrate hexahydrate, sodium hydrogen phosphate dodecahydrate and calcium chloride hexahydrate). The melting temperature of the tested PCMs is 
32 and $36{ }^{\circ} \mathrm{C}$. The evaluation was based on the calculation of $\mathrm{CR}$ as mass loss red meter and day. The samples were removed from PCMs after three, seven and 14 days. The results showed that aluminium and steel should be avoided in PCM containers due to their high corrosion rates. Slower corrosion was observed for brass and copper. Stainless steel was evaluated as corrosion resistant. The immersion corrosion test with the same metals and two salt hydrates (sodium acetate trihydrate and sodium thiosulfate pentahydrate) with melting temperature 58 and $48{ }^{\circ} \mathrm{C}$ respectively was presented by Cabeza et al. [13]. In this case the metal samples were immersed in pure PCMs and PCMs enhanced with graphite (for increased heat transfer). Immersion time was one, two, four and ten weeks. Based on the calculated CRs authors discouraged application of brass and copper as container materials for long-term storage of the tested PCMs. Aluminium, steel and stainless steel proved to be suitable container materials for both PCMs, however authors recommended monitoring of steel in contact with graphite. Study [14] generally recommends stainless steel as container material for inorganic PCMs. It evaluates CRs and industry recommendations of 6 metals (aluminium, brass, copper, steel, stainless steel and carbon steel) and 13 salt hydrate PCMs. Carbon steel is not recommended or cautiously recommended for the tested PCMs. Ushak et al. [15] investigated corrosion effect of bischofite (composed primarily of $\mathrm{MgCl}_{2} \cdot 6 \mathrm{H}_{2} \mathrm{O}$ ) and commercial $\mathrm{MgCl}_{2} \cdot 6 \mathrm{H}_{2} \mathrm{O}$ (more than $99 \%$ purity) on copper, aluminium and stainless steel. The contact times between the metals and the salts were 250, 500, 750 and $1000 \mathrm{~h}$. Calculated mass loss was used as criterion for the evaluation of corrosion effect. The highest mass loss was calculated for copper, while stainless steel showed the lowest mass loss. Moreno et al. [16] tested corrosion potential of five inorganic PCMs for cooling applications (melting range $10-15^{\circ} \mathrm{C}$ ) and six inorganic PCMs for heating application (melting range $45-48.5^{\circ} \mathrm{C}$ ). Copper, aluminium, stainless steel were selected as potential container materials. Samples of these metals were immersed in test tubes containing PCMs at constant temperature $22^{\circ} \mathrm{C}$ (cooling application) or $60{ }^{\circ} \mathrm{C}$ (heating application) for one, four and 12 weeks. Results confirmed previous studies: corrosive resistance of stainless steel for all tested inorganic PCMs. The same result was obtained from immersion test conducted by Oró et al.[17]. They tested copper, aluminium and carbon steel as well. CR was significantly slowed down by $1 \%$ of oxyethylmethylcellulose to thickening the solution in their tests. Danielik et al. [18, 19] investigated corrosion resistance of carbon steel and copper in contact with $\mathrm{Mg}\left(\mathrm{NO}_{3}\right)_{2} \cdot 6 \mathrm{H}_{2} \mathrm{O}_{\text {, }}$ $\mathrm{Mg}\left(\mathrm{NO}_{3}\right)_{2} \cdot 6 \mathrm{H}_{2} \mathrm{O}+0.5 \mathrm{wt} \% \mathrm{Mg}(\mathrm{OH})_{2}, \mathrm{Mg}\left(\mathrm{NO}_{3}\right)_{2} \cdot 6 \mathrm{H}_{2} \mathrm{O}+0.5 \mathrm{wt} \% \mathrm{Sr}(\mathrm{OH})_{2}, \mathrm{Mg}\left(\mathrm{NO}_{3}\right)_{2} \cdot 6 \mathrm{H}_{2} \mathrm{O}+$ $\mathrm{Ca}\left(\mathrm{NO}_{3}\right)_{2} \cdot 4 \mathrm{H}_{2} \mathrm{O}(1: 1)$ and $\mathrm{Ca}\left(\mathrm{NO}_{3}\right)_{2} \cdot 4 \mathrm{H}_{2} \mathrm{O}$. Melting temperatures of the studied PCMs were $42.7-$ $88,9^{\circ} \mathrm{C}$. Magnesium hydroxide and strontium hexahydrate were added due to the stabilization of supercooling of magnesium nitrate hexadyrate. During immersion time the ambient temperature was repeatedly changed from $20^{\circ} \mathrm{C}$ up to temperature slightly above the melting range of each PCM. The comparison of results in both papers [18, 19] shows that CR of carbon steel $(4.6-33.3$ $\left.\mathrm{mg} \cdot \mathrm{cm}^{-2} \cdot \mathrm{year}^{-1}\right)$ is much higher than CR of copper $\left(1.5-8.9 \mathrm{mg} \cdot \mathrm{cm}^{-2} \cdot \mathrm{year}^{-1}\right)$.

Many studies also focused on organic PCMs and their corrosion potential. Kahvaji et al. [20] selected 16 samples of potential container materials or supplementary gasket materials. These included nine metals or metal alloys and seven plastics. Study focused on the compatibility potential of these materials with five fatty acids and one alcohol representing the PCMs. Materials were immersed in liquid PCMs with temperature of $75^{\circ} \mathrm{C}$ for one, six and 12 weeks. The evaluation was based on the results from CR calculations. Stainless steel alloys and aluminium alloys showed good compatibility with all PCMs. Ferrer et al. [21] tested compatibility of selected metals (stainless steel SS-316 and SS-304, copper, aluminium and carbon steel), two commercially available PCMs (inorganic SP21E and bio-based PureTemp 23) and two fatty acid eutectics. The melting range of all PCMs was between 21 and $23^{\circ} \mathrm{C}$. Immersion times for evaluation were one, four and 12 weeks. Based on the $\mathrm{CR}$ calculation results they concluded that all tested metals can be recommended as container for bio-based PCM (PureTemp 23). Stainless steel and copper also proved resistant to inorganic PCM. On the other hand both fatty acid eutectics caused low corrosion on copper only. Sari et Kaygusuz [22] presented study focused on the thermal stability of stearic acid, palmitic acid, myristic acid and lauric acid and their compatibility with carbon steel, stainless steel, aluminium and copper. The evaluation was based on the gravimetric and metallographic analysis. Highest CRs were 
calculated for steel C20 and copper in contact with myristic acid and copper immersed in stearic acid. In contrast, the lowest $\mathrm{CR}$ was calculated for stainless steel. Browne et al. [23] chose aluminium, brass, copper, stainless steel and mild steel for corrosion experiments with capric acid, capric-palmitic acid, capric-lauric acid, sal hydrate SP22 and Micronal ${ }^{\circledR}$. Authors concluded that only stainless steel is suitable container material for all PCMs tested. All metals except aluminium were recommended for use in combination with SP 22. Similarly, all metals except mild steel were recommended for applications with Micronal ${ }^{\circledR}$. Caution was recommended for other metal-PCM pairs.

Presented literature review shows the necessity for compatibility tests of selected metal and organic and inorganic PCMs pairs. It also shows lack of knowledge on the performance of commercially available PCMs (in metal containers) with melting temperature range suitable for installation in the occupied rooms. This issue is stressed by the authors of this paper, who performed a three-year experiment focused on the influence of PCMs on the indoor environment: Figure 1, left shows the installation of aluminium containers fixed on the walls and suspended ceiling in test room at Brno University of Technology. The original aim of this installation was evaluation of suitability of LHTES integration in building structures for improving indoor thermal comfort. However leakage of PCM from many containers (Figure 1, right) was observed during and after the experiment. This was the starting point of the author's research on PCM-metal compatibility. This study follows the literature review above and evaluates impact of long term exposure (visual changes, corrosion) to PCMs on selected metals: aluminium, brass, copper and carbon steel.
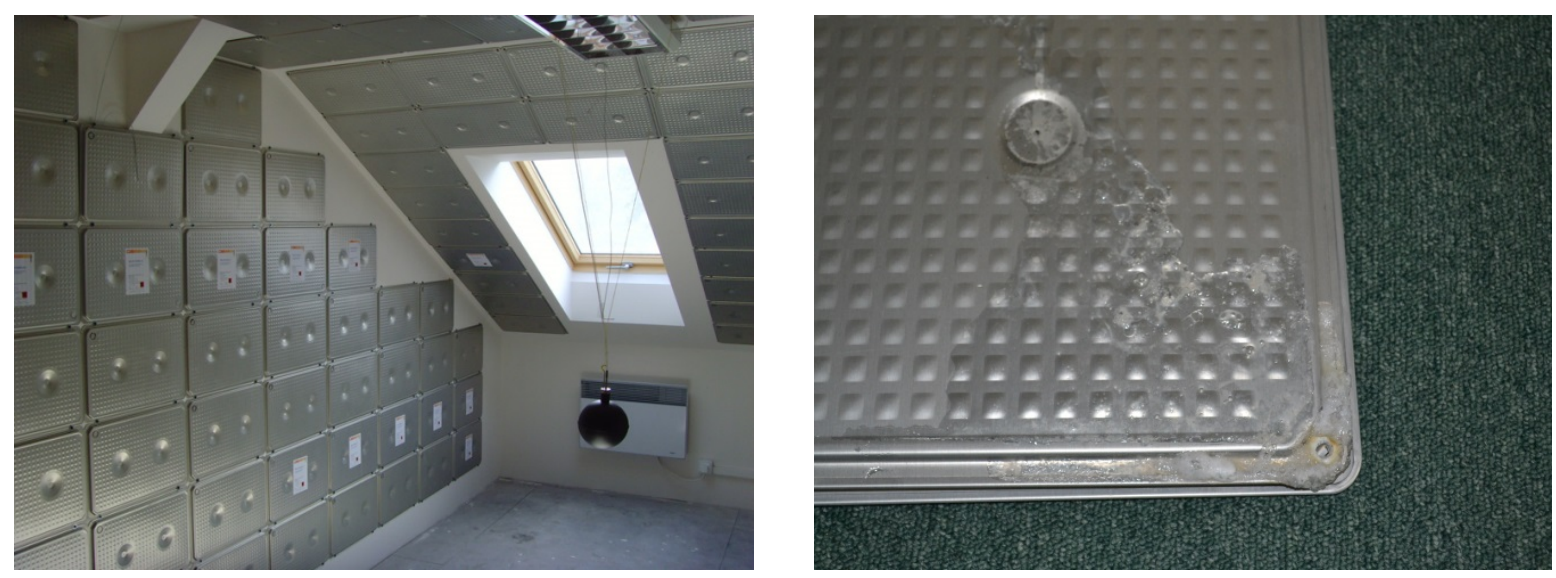

Figure 1. PCM encapsulated in aluminium container: (left) Experimental installation in the test room; (right) PCM leakage on the surface of aluminium container.

\section{Results}

This section presents the results of the compatibility test described in Section 4 . The evaluation of the results is divided in two parts. First part includes visual evaluation of the samples, i.e. the color, shape and other changes on the surface of samples encountered after removal from the PCMs. Second part includes evaluation of the CRs that was calculated according to equation (1) described in Section 4.

Immersion in organic PCMs caused no visual changes on surface of brass, aluminium and carbon steel samples. Change the color on part of the surface (darker stains) and tarnishing occurred on copper samples. The extent of these changes increased with longer exposure to the PCMs (see Figure 2, top). More pronounced changes were encountered on samples immersed in inorganic PCMs. All samples were tarnished as early as one week after immersion. Noticeable dark brown stains appeared on the surface of copper and brass samples. Corrosion also occurred on the surface of copper (blue corrosion) and carbon steel (dark red and brown corrosion) samples. Progress of tarnishing and corrosion in time is visible in Figure 2 (bottom). 

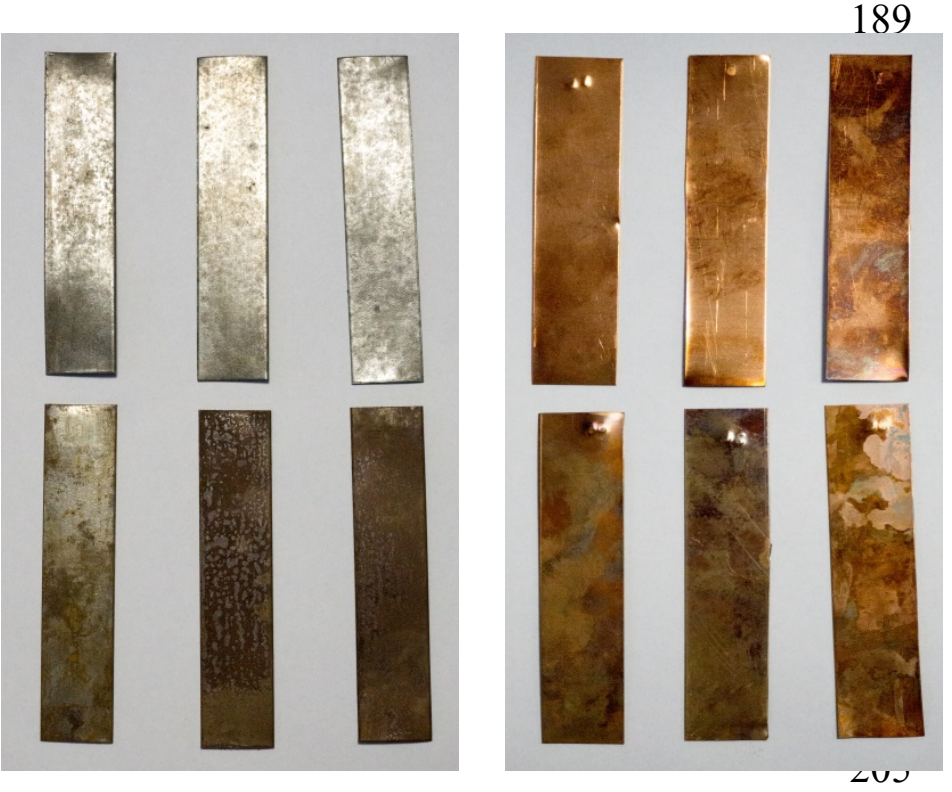

Figure 2. Corrosion, change of appearance and color of the metals samples after testing.

(left) Carbon steel samples removed from organic PCM Linpar 1820 (top row) and inorganic PCM Rubitherm RT SP25 (bottom row) after one, four and twelve weeks (left to right).

(right) Copper samples removed from organic PCM Linpar 17 (top row) and inorganic PCM Rubitherm RT SP25 (bottom row) after one, four and twelve weeks (left to right).

Table 1. CRs of tested metals exposed to particular PCMs (organic Linpar and inorganic Rubitherm)

\begin{tabular}{lccccc}
\hline \multirow{2}{*}{ Metal } & Exposure & \multicolumn{4}{c}{ Corrosion rate $\left[\mathrm{mg}^{\left.-\mathrm{cm}^{-2} \cdot \mathrm{year}^{-1}\right]}\right.$} \\
& time & Linpar 17 & Linpar 1820 & RT SP22 & RT SP25 \\
\hline \multirow{3}{*}{ Carbon steel } & 1 weeks & 4.058 & 2.562 & 11.236 & 13.897 \\
& 4 weeks & 0.589 & 0.492 & 1.723 & 3.413 \\
& 12 weeks & 0.214 & 0.135 & 0.712 & 1.029 \\
\hline \multirow{3}{*}{ Aluminium } & 1 weeks & 1.049 & 0.762 & 1.765 & 1.024 \\
& 4 weeks & 0.219 & 0.190 & 0.991 & 0.292 \\
& 12 weeks & 0.053 & 0.033 & 0.460 & 0.194 \\
\hline \multirow{3}{*}{ Copper } & 1 weeks & 1.807 & 2.564 & 6.049 & 5.400 \\
& 4 weeks & 0.525 & 0.572 & 1.013 & 1.863 \\
Brass & 12 weeks & 0.174 & 0.072 & 0.152 & 1.004 \\
\hline
\end{tabular}

Table 1, Figure 3 and Figure 4 show the CR values of the tested metals in all PCMs. When considering organic PCMs, the results show that higher CR were achieved with long-term immersion of samples in Linpar 17. The highest values were achieved in case of carbon steel, where the CR exceeded $4.0 \mathrm{mg} \cdot \mathrm{cm}^{-2}$.year ${ }^{-1}$. It should be noted that copper and brass samples immersed in Linpar 1820 had higher CR after one-week immersion. The difference was almost $30 \%$ in case of copper. However CR results of these metals obtained after longer exposure also "favour" Linpar 17. The CR curves of metal samples immersed in inorganic PCMs (Figure 4) are very similar to those in organic PCMs. The difference is in their scale: CRs of metals in inorganic PCMs are much higher. This is illustrated in Figure 5, which shows CR curves of copper and carbon steel (highest CRs of all four metals) The values gradually increase from aluminium to brass, copper and finally carbon steel.

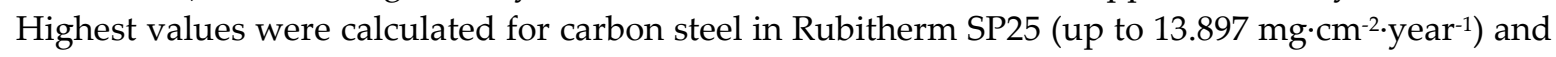
copper in Rubitherm SP22 (up to $6.049 \mathrm{mg} \cdot \mathrm{cm}^{-2} \cdot \mathrm{year}^{-1}$ ). 

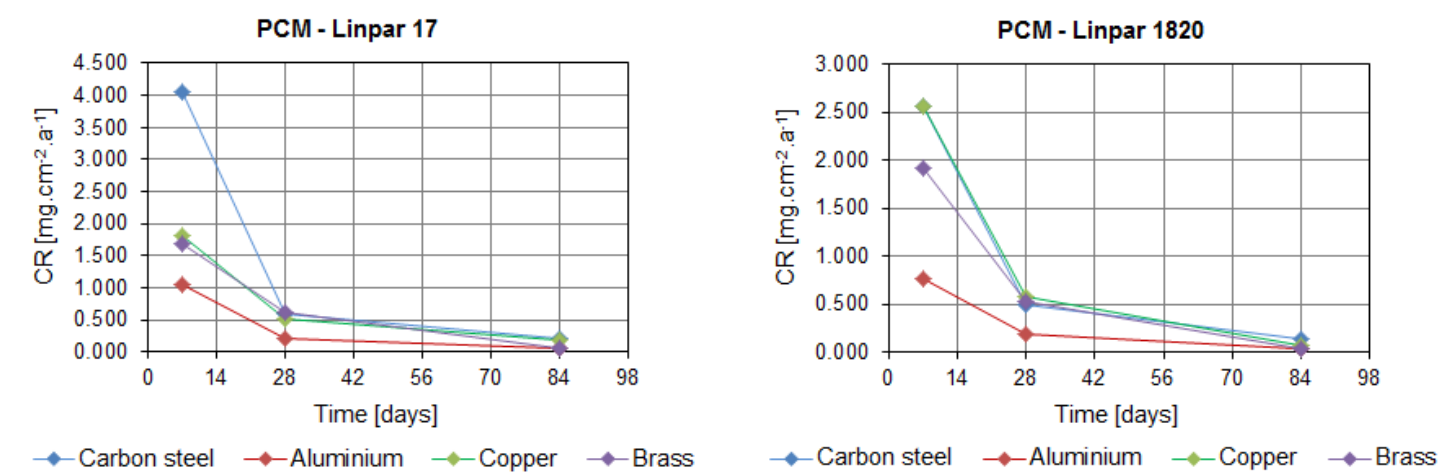

Figure 3. Dependence of CR of tested metals on time of immersed in organic PCMs: (left) in Linpar 17; (right) in Linpar 1820
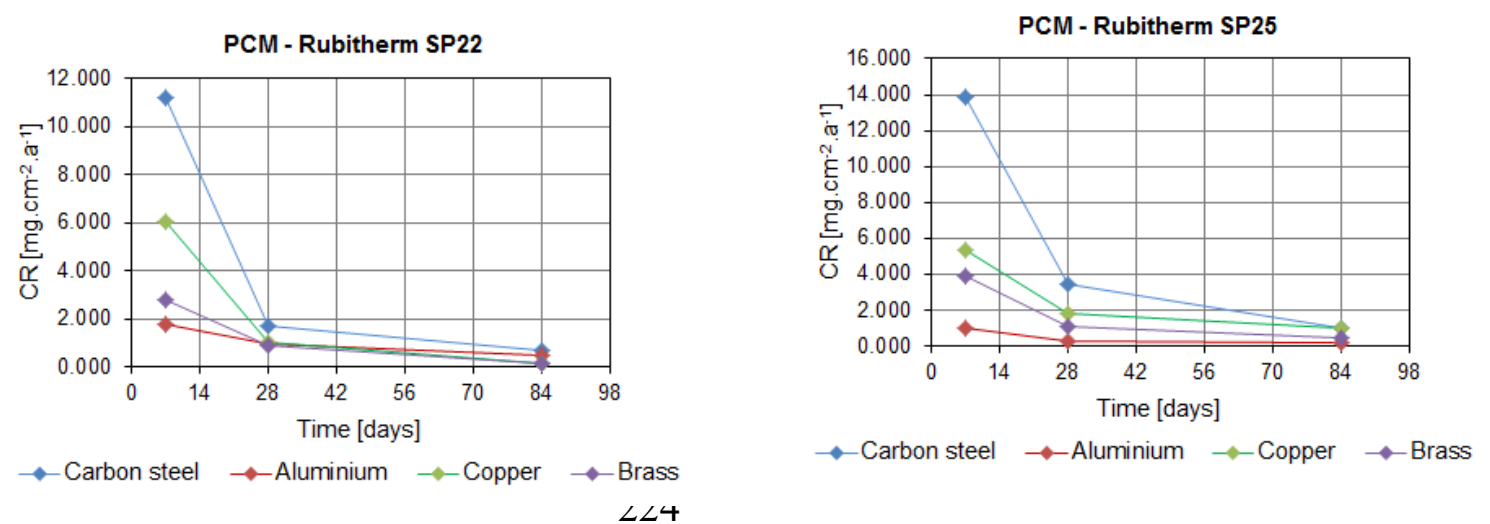

Figure 4. Dependence of CR of tested metals on time of immersed in inorganic PCMs: (left) in Rubitherm SP22; (right) in Rubitherm SP25
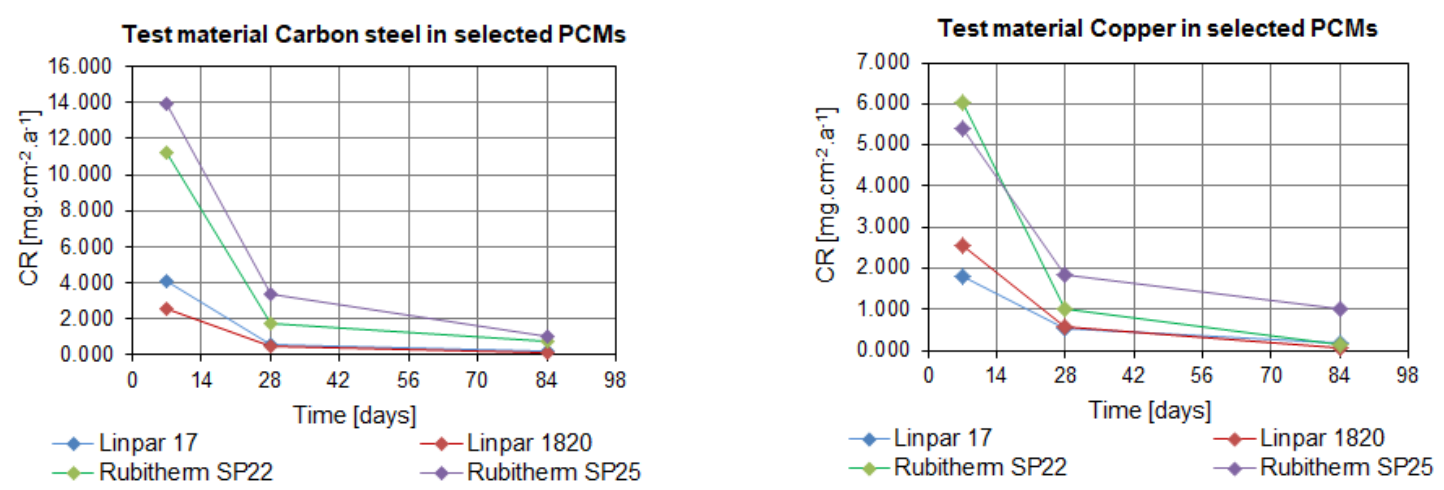

Figure 5. Comparison of the dependence of CR of selected metals in both types organic and inorganic PCMs: (left) for carbon steel samples; (right) for copper samples

Another evaluated parameter was the mass loss $\Delta m$, which is an important information for the evaluation of corrosion effect. The highest mass loss was calculated for copper and carbon steel samples in Rubitherm SP25. It reached $9.6 \mathrm{mg}$ for copper after 12 week of immersion and $11.2 \mathrm{mg}$ for carbon steel after 4 week of immersion (see in Figure 6). In contrast, the lowest mass losses of all tested metals were calculated in samples immersed in organic PCM Linpar 17. In case of aluminium it ranged between 0.5 to $0.8 \mathrm{mg}$ depending on the length of immersion. In contrast, aluminium achieved much higher mass loss of 1.4 to $4.4 \mathrm{mg}$ in inorganic PCMs Rubitherm SP22. 


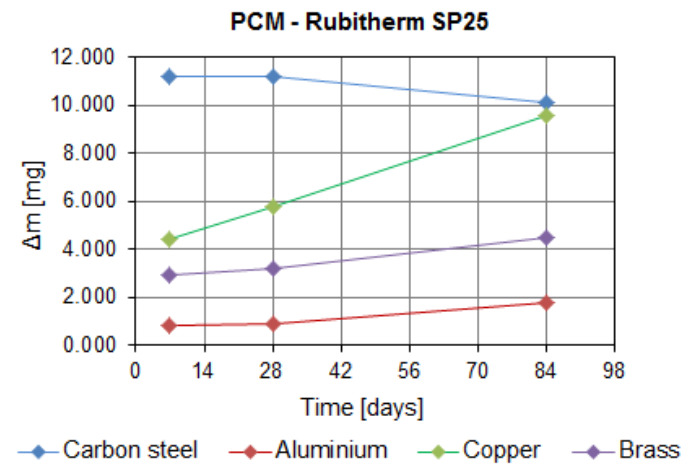

Figure 6. The mass loss of all metals in inorganic Rubitherm SP25

\section{3. Discussion}

The results of the study are compiled in Table 2. It shows the range of calculated CR values, surface changes, occurrence of corrosion and evaluation according to the Guide for corrosion weight loss used in the industry [17, 21]. Most tested metal-PCM combinations were evaluated as "Recommended" according to this guide. The exception is carbon steel in combination with inorganic PCMs, which achieved "Cautiously recommended" level. Regardless of the Guide it seems appropriate to further discourage use of copper and carbon steel in combination with inorganic PCMs due to higher CR values, significant mass loss and visible changes on the surface of the samples.

Table 2. Classification of selected PCM-metal combinations according to the CR parameter $\left[\mathrm{mg} \cdot \mathrm{cm}^{-2} \cdot\right.$ year $\left.^{-1}\right]$ and recommendation according to final appearance of samples (based on Table 1.)

\begin{tabular}{|c|c|c|c|c|c|}
\hline \multirow{2}{*}{$\begin{array}{l}\text { Material } \\
\text { (metals) }\end{array}$} & \multirow{2}{*}{ Criterion } & \multicolumn{4}{|c|}{ PCMs (organic group Linpar and inorganic group RT) } \\
\hline & & Linpar 17 & Linpar 1820 & RT SP22 & RT SP25 \\
\hline \multirow{3}{*}{ Carbon steel } & CR & 0.21 to 4.05 & 0.13 to 2.56 & 0.71 to 11.23 & 1.02 to 13.89 \\
\hline & Corrosion & $\begin{array}{l}\text { no corrosion } \\
\text { surface - no } \\
\text { change }\end{array}$ & $\begin{array}{l}\text { no corrosion } \\
\text { surface - no } \\
\text { change }\end{array}$ & $\begin{array}{l}\text { corrosion - red } \\
\text { colour }\end{array}$ & $\begin{array}{l}\text { corrosion - red } \\
\text { colour }\end{array}$ \\
\hline & Recommendation & recommended & recommended & $\begin{array}{l}\text { cautiously } \\
\text { recommended }\end{array}$ & $\begin{array}{l}\text { cautiously } \\
\text { recommended }\end{array}$ \\
\hline \multirow{3}{*}{ Aluminium } & $\mathrm{CR}$ & 0.05 to 1.05 & 0.03 to 0.76 & 0.46 to 1.76 & 0.19 to 1.02 \\
\hline & Corrosion & $\begin{array}{l}\text { no corrosion, } \\
\text { shiny surface }\end{array}$ & $\begin{array}{l}\text { no corrosion, } \\
\text { shiny surface }\end{array}$ & $\begin{array}{l}\text { no corrosion, } \\
\text { surface } \\
\text { tarnish, } \\
\text { occurrence of } \\
\text { cracks }\end{array}$ & $\begin{array}{l}\text { no corrosion, } \\
\text { surface tarnish }\end{array}$ \\
\hline & Recommendation & recommended & recommended & recommended & recommended \\
\hline \multirow{3}{*}{ Copper } & CR & 0.17 to 1.80 & 0.07 to 2.56 & 0.15 to 2.79 & 1.00 to 5.40 \\
\hline & Corrosion & $\begin{array}{l}\text { no corrosion, } \\
\text { shiny to matt } \\
\text { surface with } \\
\text { time }\end{array}$ & $\begin{array}{l}\text { no corrosion, } \\
\text { shiny to matt } \\
\text { surface with } \\
\text { time }\end{array}$ & $\begin{array}{l}\text { corrosion - } \\
\text { blue colour, } \\
\text { surface tarnish }\end{array}$ & $\begin{array}{l}\text { corrosion - } \\
\text { blue colour, } \\
\text { surface tarnish }\end{array}$ \\
\hline & Recommendation & recommended & recommended & recommended & recommended \\
\hline \multirow{3}{*}{ Brass } & CR & 0.04 to 1.68 & 0.04 to 1.92 & 0.16 to 6.04 & 0.47 to 3.88 \\
\hline & Corrosion & $\begin{array}{l}\text { no corrosion, } \\
\text { shiny surface }\end{array}$ & $\begin{array}{l}\text { no corrosion, } \\
\text { shiny surface }\end{array}$ & $\begin{array}{l}\text { no corrosion, } \\
\text { surface tarnish }\end{array}$ & $\begin{array}{l}\text { no corrosion, } \\
\text { surface tarnish }\end{array}$ \\
\hline & Recommendation & recommended & recommended & recommended & recommended \\
\hline
\end{tabular}


The results also confirm the literature review (see Section 1) regarding significant differences in exposure of metals to organic and inorganic PCMs (in favour of organic PCMs). All metals demonstrated good compatibility (minimum to no visible changes and low CR) with organic PCMs. This is also confirmed by lower mass loss of tested metals, where the maximum value in organic PCM was $2.1 \mathrm{mg}$ in case of carbon steel in Linpar 1820. This is almost six times lower value compared to the mass loss of carbon steel in inorganic PCM Rubitherm SP25. The results indicate low aggressiveness of tested organic PCMs and confirm suitability of tested metals in the role of their containers.

\section{Materials and Methods}

Long-term experimental measurements were performed to verify compatibility of two types of PCMs (organic and inorganic) with selected metals (representing possible container materials). The aim of the experiment was elimination of metals unsuitable for the role of long-term PCM containers (integrated in building structures). The evaluation was based on weight loss and surface changes (i.a. corrosion, change of color, swelling of the samples).

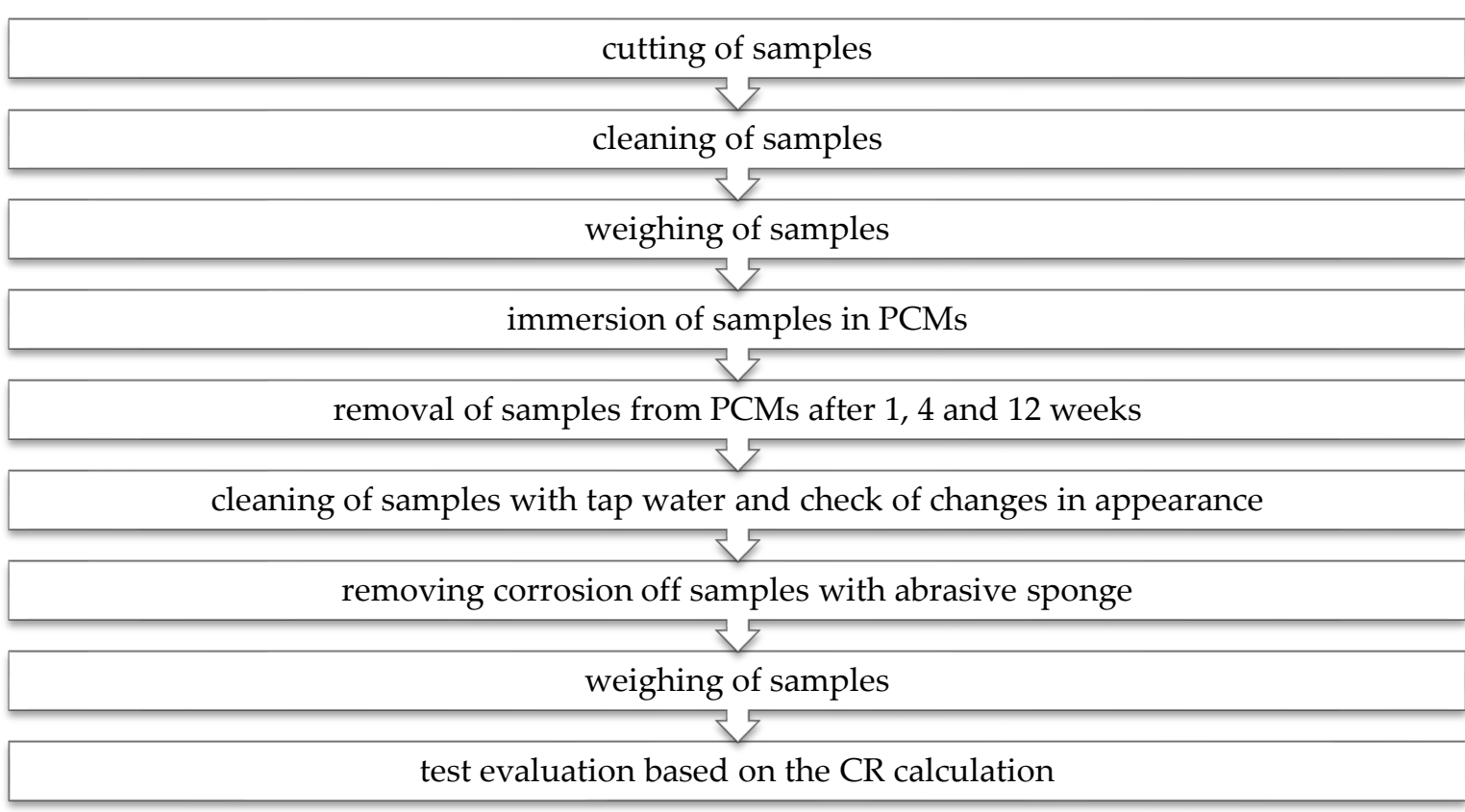

Figure 7. Experimental procedure.

Four metals applicable in the role of PCM containers (based on literature review in Section 1) were selected for the experiment: carbon steel, aluminium, copper and brass. The reasons for selection of the particular metals include low costs and excellent market availability. 36 samples were prepared out of each metal (144 samples in total) for the testing (see Figure 7, right). The samples were divided into 12 sets of 3 samples for each metal. Individual samples were approximately $2.0 \mathrm{~cm}$ wide, $10.0 \mathrm{~cm}$ high and, $0.1 \mathrm{~cm}$ (carbon steel) or $0.05 \mathrm{~cm}$ (other metals) thick.

Table 3 includes the parameters and product names of the tested PCMs. Paraffin-based Linpar 17 and Linpar 1820 represent organic PCMs in the experiment, while salt-hydrate-based Rubitherm SP22 and Rubitherm SP25 represent inorganic PCMs. Parameters in table 3. were acquired using Different Scanning Calorimeter (DSC). 
Table 3. Parameters of selected PCMs (measured during melting) with DSC.

\begin{tabular}{cccccc}
\hline Type & $\begin{array}{c}\text { Product } \\
\text { name }\end{array}$ & Manufacturer & $\begin{array}{c}\text { Latent } \\
\text { heat } \\
{\left[\mathrm{J} \cdot \mathbf{g}^{-1}\right]}\end{array}$ & $\begin{array}{c}\text { Onset } \\
\text { temperature } \\
{\left[{ }^{\circ} \mathrm{C}\right]}\end{array}$ & $\begin{array}{c}\text { Peak } \\
\text { temperature } \\
{\left[{ }^{\circ} \mathrm{C}\right]}\end{array}$ \\
\hline inorganic & SP22 & Rubitherm & 145 & 14 & 25 \\
inorganic & SP25 & Rubitherm & 122 & 18 & 28 \\
organic & Linpar 17 & Sasol & 152 & 21 & 22 \\
organic & Linpar 1820 & Sasol & 141 & 24 & 27 \\
\hline
\end{tabular}
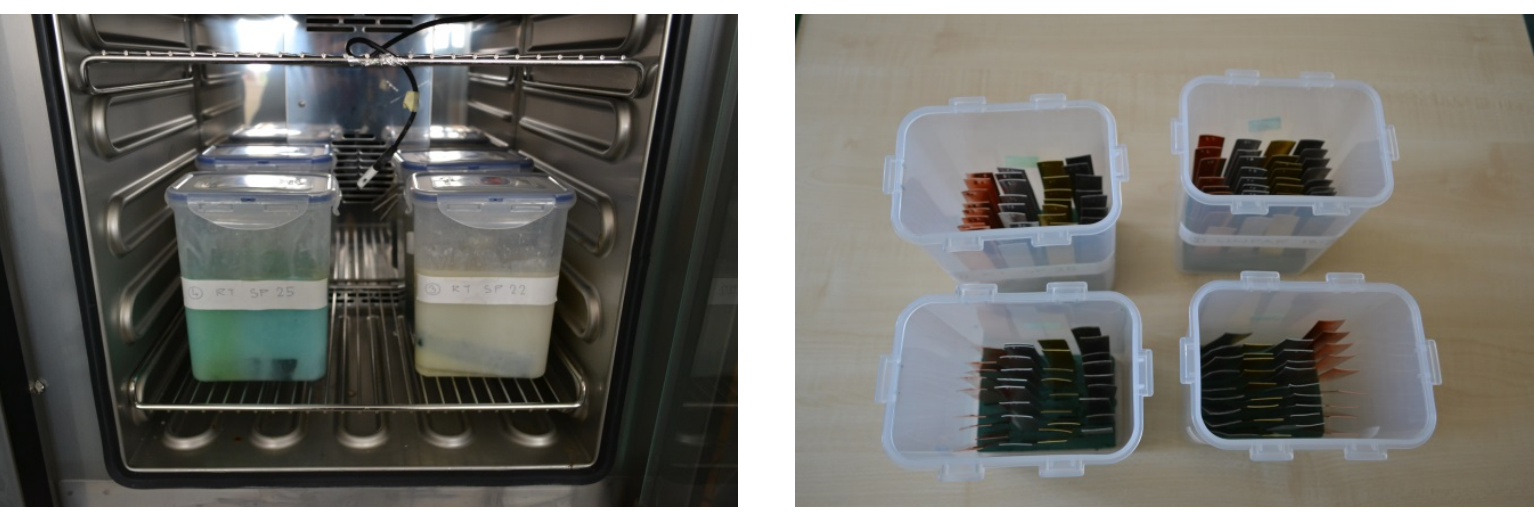

Figure 8. Metal samples prepared for corrosion testing: (left) Test beakers placed in environmental chamber; (right) Samples in test beakers.

The parameter evaluating of metal-PCM combinations in this study is corrosion rate (CR) defined according to methodology described in [17] and [21]. The Guide for corrosion weight loss used in the industry $[16,17,21]$ (see Table 4 ) was utilized for the classification and verbal evaluation of $\mathrm{CR}$ in this study. CR was defined as a change of mass $\Delta m$ relative to surface area of the metal sample in specific experimental time period. The change in mass is defined as the difference in initial sample weight and the weight at the end of the particular time period.

$$
C R=\Delta m / A \cdot\left(t_{0}-t\right)
$$

where $C R$ is the corrosion rate in $\mathrm{mg} \cdot \mathrm{cm}^{-2} \cdot \mathrm{year}^{-1}, \Delta m$ is mass loss (in $\mathrm{mg}$ ) and it is defined by the relation $\Delta m=m\left(t_{0}\right)-m(t)$. The value $m\left(t_{0}\right)$ is initial weight of the sample (in $\mathrm{mg}$ ) before immersion in PCMs and $m(t)$ is final weight of the sample (in mg) after removal from PCMs. The area of each sample is expressed by value A (in $\left.\mathrm{cm}^{2}\right)$ and $\left(t_{0}-t\right)$ is the experimental time of PCMs exposure (in years).

Table 4. Guide for corrosion weight loss used in the industry $[17,21]$

\begin{tabular}{cl}
$\begin{array}{c}\text { CR } \\
\text { [mg.cm-2.year-1] }\end{array}$ & Recommendation \\
\hline$>1000$ & Completely destroyed within days \\
100 to 999 & Not recommended for service greater than a month \\
50 to 99 & Not recommended for service greater than 1 year \\
10 to 49 & Caution recommended, based on the specific application \\
0.3 to 9.9 & Recommended for long term service \\
$<0.2$ & Recommended for long term service; no corrosion, other than as a \\
& result of surface cleaning, was evidenced \\
\hline
\end{tabular}


All metal samples were clearly labelled, purified and weighted on microscales prior to the experiment. Excessive material (residuals after cutting) was mechanically removed. Afterwards the samples were visually checked, inserted into supporting foam holder (see Figure 8, right) and placed into testing beakers. There they were fully immersed in liquid PCMs. Special care was taken to prevent mutual contact of metal samples (causing uneven exposure of the surface to the PCM).

The test beakers were placed into a small environmental chamber (see in Figure 8, left). There they were exposed to repeating temperature cycling with temperatures ranging from $15^{\circ} \mathrm{C}$ to $40^{\circ} \mathrm{C}$. The cycle consisted of four phases, each lasting for two hours (see Figure 9). The cycle started with linear temperature raise (to $40^{\circ} \mathrm{C}$ ) during first phase. Second phase comprised maintaining of the temperature at this level. The temperature was linearly reduced to $15^{\circ} \mathrm{C}$ in the third phase. This temperature was maintained during fourth phase of the cycle. The temperature cycling lasted for twelve weeks (84 days).

Sets of samples were withdrawn from the beakers on given time after one week ( 7 days), four week (28 days) and 12 week ( 84 days) exposure to the PCMs.

\section{Temperature cycle in Chamber}

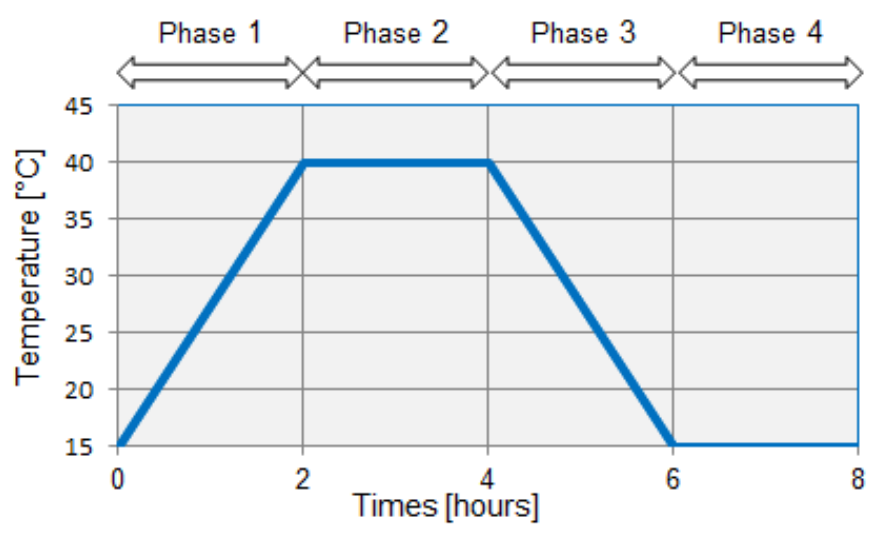

Figure 9. Temperature cycle repeated in the small environmental chamber for the duration of the experiment.

After removal from the test beakers, the samples were visually inspected and cleaned of any liquid residues. Corrosion was removed using abrasive sponge. Cleaned samples were weighted on microscale. The weight of each sample was rounded to $0.1 \mathrm{mg}$. One sample from each set was selected using the median value. The weight change of the selected samples was used for calculating CR afterwards. This method was selected to minimize errors and eliminate extreme values.

\section{Conclusions}

This study deals with the issue of compatibility of selected metals and (organic and inorganic) PCMs. It deals with the selection of suitable metal for the role of container material for long term PCM encapsulation. Therefore samples of four metals (aluminium, brass, copper and carbon steel) were tested in combination with four PCMs for up to 12 weeks.

The initial premise of the experiment was that exposure the surface of metals to effects of PCMs will affect their shape, surface flatness, color and perhaps the occurrence of surface corrosion will be detected. Literature review suggested that copper and carbon steel are unsuitable for long-term exposition to PCMs. This assumption was confirmed, i.e. the both metals showed signs of surface corrosion and change of color at the end of the experiment. Moreover they both achieved higher CR values and more pronounced mass loss compared to other tested metals (in inorganic PCMs). The results indicate that aluminium is the best (out of the tested metals) suited for the role of PCM container. It had the lowest mass loss and CR and suffered only minimal visual changes on the surface. This long-term stability should ensure durability of whole LHTES system (e.g. prevent leakage due to corrosion). 
Author Contributions: conceptualization, S.B. and M.O.; methodology, S.B.; formal analysis, K.S.; test procedure, S.B. and M.O.; resources, M.O.; evaluation, S.B.; writing-original draft preparation, S.B. and M.O.; writing - review and editing, K.S.; supervision, M.O.; project administration, M.O.; funding acquisition, M.O.

Funding: This research was funded by Czech Science Foundation, grant number 19-20943S “Compatibility of plastics and metals with latent heat storage media for integration in buildings".

Conflicts of Interest: The authors declare no conflict of interest.

\section{References}

1. Arunachalam, S. Latent Heat Storage: Container Geometry, Enhancement Techniques, and Applications-A Review. Journal of Solar Energy Engineering 2019, 141, 050801-1-050801-14

2. Milián, Y.E.; Gutiérrez, A.; Grádea, M.; Ushak, S. A review on encapsulation techniques for inorganic phase change materials and the influence on their thermophysical properties. Renewable and Sustainable Energy Reviews 2017, 73, 983-999

3. Nazir, H.; Batool, M.; Osorio, F.J.B.; Isaza-Ruiz, M.; Xu, X.; Vignarooban, K.; Phelan, P.; Inamuddin, Kannan, A.M. Recent developments in phase change materials for energy storage applications: A review. International Journal of Heat and Mass Transfer 2019, 129, 491-523

4. Dinker, A.; Agarwal, M.; Agarwal, G.D. Heat storage materials, geometry and applications: A review. Journal of Energy Institute 2017, 90, 1-11

5. Mehling, H.; Cabeza L.F. Heat and cold storage with PCM. An up to date introduction into basics and applications, $1^{\text {st }}$ ed.; Springer-Verlag Berlin and Heidelberg GmbH \& Co. KG, Germany, 2008, pp. 97-100

6. Lane, G.A. Solar heat storage: Latent heat materials. Volume II. Technology. CRC Press, Inc., United States, 1986, pp. 95-98

7. Khan, Z.; Khan, Z.; Ghafoor, A. A review of performance enhancement of PCM based latent heat storage system within the context of materials, thermal stability and compatibility. Energy Conversion and Management 2016, 115, 132-158

8. Krishna, D.J.; Shinde, A. Step by Step Methodology for the Assessment of Metal Corrosion Rate with PCMs Suitable for Low Temperature Heat Storage Applications. Materials Today: Proceedings 2017, 4, 10039-10042

9. ASTM G1 - 03 Standard Practice for Preparing, Cleaning, and Evaluating Corrosion Test Specimens. Available online: $h t t p: / / m a t e r i a l s t a n d a r d . c o m / a s t m-g /$ (accessed on July 10 th 2019)

10. Calabrese, L.; Brancato, V.; Palomba, V.; Proverbio, E. An experimental study on the corrosion sensitivity of metal alloys for usage in PCM thermal energy storages. Renewable Energy 2019, 138, 1018-1027

11. Farrell, A.J; Norton, B.; Kennedy, D.M. Corrosive effect of salt hydrate phase change materials used with aluminium and copper. Journal of Materials Processing Technology 2006, 176, 198-205

12. Cabeza, L.F.; Roca, I.J.; Badia, F.; Mehling, H.; Hiebler, S.; Ziegler, F. Immersion corrosion tests on metal-salt hydrate pairs used for latent heat storage in the 32 to $36{ }^{\circ} \mathrm{C}$ temperature range. Materials and Corrosion 2001, 52, 140-146

13. Cabeza, L.F.; Roca, J.; Nogués, M.; Mehling, H.; Hiebler, S. Immersion corrosion tests on metal-salt hydrate pairs used for latent heat storage in the 48 to $58{ }^{\circ} \mathrm{C}$ temperature range. Materials and Corrosion 2002, 53, 902-907

14. Fernández, A.I.; Solé, A.; Giró-Paloma, J.; Martínez, M.; Hadjieva, M.; Boudenne, A.; Constantinescu, M.; Anghel, E.M.; Malikova, M.; Krupa, I.; Peñalosa, C.; Lázaro, A.; Paksoy, H.O.; Cellat, K.; Vecstaudža, J.; Bajare, D.; Sumiga, B.; Boh,B.; Haussmann, T.; Gschwander, S.; Weber, R.; Furmanski, P.; Jaworski, M.; Cabeza, L.F. Unconventional experimental technologies used for phase change materials(PCM)characterization:part2 - morphological and structural characterization, physico-chemical stability and mechanical properties. Renewable and Sustainable Energy Reviews 2015, 43, 1415-1426

15. Ushak, S.; Marín, P.; Galazutdinova, Y.; Cabeza, L.F.; Farid, M.M.; Grágeda. Compatibility of materials for macroencapsulation of inorganic phase change materials: Experimental corrosion study. Applied Thermal Engineering 2016, 107, 410-419

16. Moreno, P.; Miró, L.; Solé, A.; Barreneche, C.; Solé, C.; Martonell, I.; Cabeza, L.F. Corrosion of metal and metal alloy containers in contact with phase change materials (PCM) for potential heating and cooling applications. Applied Energy 2014, 125, 238-245 
411 17. Oró, E.; Miró, L.; Barreneche, C.; Martonell, I.; Farid, M.M., Cabeza, L.F. Corrosion of metal and polymer 412 413 414 415 416 417 418 containers for use in PCM cold storage. Applied Energy 2013, 109, 449-453

18. Danielik, V.; Šoška, P.; Felgerová, K.; Zemanová, M. The corrosion of carbon steel in nitrate hydrates used as phase change materials. Materials and Corrosion 2017, 68, 416-422

19. Danielik, V.; Šoška, P.; Felgerová, K. Corrosive effects of nitrate-containing phase change materials used with copper 2016, Acta Chimica Slovaca, 9, 75-83

20. Kahwaji, S.; Johnson, M.B; Kheirabadi, A.C.; Groulx, D.; White, M.A. Fatty acids and related phase change materials for reliable thermal energy storage at moderate temperatures. Solar Energy Materials and Solar Cells 2017, 167, 109-120

21. Ferrer, G.; Solé, A.; Barreneche, C.; Martonell, I.; Cabeza, L.F. Corrosion of metal containers for use in PCM energy storage. Renewable Energy 2015, 76, 465-469

22. Sari, A.; Kaygusuz, K. Some fatty acids used for latent heat storage: thermal stability and corrosion of metals with respect to thermal cycling. Renewable Energy 2003, 28, 939-948

23. Browne, M.; Boyd, E.; McCormack, S.J. Investigation of the corrosive properties of phase change materials in contact with metals and plastic. Renewable Energy 2017, 108, 555-568 